\title{
Luz para além do clarão
}

\section{Light beyond the glare}

Flaviana Xavier Antunes Sampaio' 
Resumo

A luz ao mesmo tempo que é evidente também é subjetiva. A escuridão que conota ausência(s) de luz sempre é repleta de sombras. O campo de percepção tende a ser direcionado não apenas pelo que vemos, mas principalmente pelo modo que enxergamos. Compartilho neste escrito ideias de uso de luz/sombra que culminaram na Intervenção Alvorada - Ação do Grupo de Pesquisa Alvorada: Estratégias de Criação Cênica a partir de experimentos em lluminação, Cenário, Figurino e Maquia-gem (CNPQ/UESB).

Palavras-chave: Experimentação Cênica; Sombra; Iluminação.

\section{Abstract}

Light is a phenomenon that is at the same time evident and subjective. The darkness that connotes absence(s) of light is always full of shadows. The field of perception tends to be directed not only by what we see but mainly by the way we see. In this text I share ideas about the use of light/shadow which culminated in the Intervention Alvorada - Action of the Research Group Alvorada: Estratégias de Criação Cênica a partir de experimentos em Iluminação, Cenário, Figurino e Maquiagem (CNPq / UESB).

Keywords: Theatrical experimentation; shadow; lighting design.

ISSN: 1414.5731

E-ISSN: 2358.6958

1 Doutoranda em Dança na University of Chichester - UK. Profa. Na 


\section{Passos de iniciação}

Atualmente leciono nos cursos de Licenciatura em Dança e Licenciatura em Tea tro da Universidade Estadual do Sudoeste da Bahia (UESB) e, embora tenha feito mes trado na temática de "Iluminação Cênica", práticas de criação, montagem e concepção (desde 2004) e dois cursos na área, não vislumbrava ensinar nesse campo, o qual possuo um profundo respeito e anunciada falta de domínio pleno.

Toda vez que ministro a disciplina "lluminação" informo sobre minha paixão, curiosidade e interesse de introduzir conteúdos técnicos, históricos e conceituais -com inclinação maior para este último aspecto. Minha feliz incompletude no campo da luz cênica visa demonstrar a volubilidade do mercado nesta área e também valorizar os técnicos teatrais que possuem um fino saber, embora boa parte de sua aprendizagem ocorra apenas na prática, sem curso formal ou aquisição de certificado a conferir-lhe mais notoriedade.

Diante de uma carga horária de 60 horas e extrema vontade de proporcionar os estudos em lluminação como previsto na ementa, identifiquei logo na primeira experiência,

em 2011, que não conseguiria aprofundar os questionamentos no diálogo da luz na cena. Essa deficiência partia do pressuposto da heterogeneidade da turma, falta de equipamento e estrutura física, e diversificação da bibliografia.

A constatação de que o estudo na disciplina "Iluminação" poderia sugerir atualizações e novos saberes, mobilizou o desejo de criar um plano de estudo que compreendesse não só a luz, mas a visualidade da cena de modo articulado. Daí originou

o Grupo de Pesquisa Alvorada: Estratégias de Criação Cênica a partir de experimentos em Iluminação, Cenário, Figurino e Maquiagem/ CNPQ (http://dgp.cnpq.br/dgp/espelhogrupo/6661766215796202).

Somada à vontade de investigar e compartilhar materiais de modo mais informal e flexível, eu notava um potente interesse dos estudantes de Dança e Teatro que, estando num curso de licenciatura, poderiam experimentar questões criativas e pedagógicas durante os encontros. Todas as quintas das 18:30h às 20:30h durante pouco mais de dois anos (Junho/2012 a Agosto/2014) provocamos discussões acerca de visualidade.

O norte principal para proposição do grupo foi o entendimento de que ao atuar como educador é próprio do profissional de Dança e Teatro a produção de espetáculos. $\mathrm{O}$ cuidado em utilizar as informações visuais de modo coerente, integrada ao argumento da obra, ajuda aos diretores teatrais e coreógrafos. Este tratamento repercute uma facilidade nas escolhas determinantes da montagem.

Estudos no livro Teatro de cordel e formação da cena de Armindo Bião possibilita, dentre outras questões, reflexões sobre produção em Artes Cênicas no Brasil. Em uma seção destinada à formação para cena, Bião aborda pesquisa atrelada a busca de fatos de modo sistemático no campo da pós-graduação e conclui:

E isso não é estrangeiro à criação e produção artísticas. Não se faz arte sem pesquisa, sobretudo na Universidade; o que é escasso é o processo rotineiro de sistemati-zação, através de projetos e de relatórios específicos, segundo os modelos e rotinas criados para as artes cênicas ditas "duras", com destaque para a área de ciência e tecnologia (Bião, 2009, p.266). 
Os educadores de Dança e Teatro que atuam como pesquisador/artista tendem a ter mais liberdade e consciência de suas criações a partir de estudos sistemáticos em visualidade. 0 exercício de refletir e catalogar achados e inquietações suscita novos saberes. Desse modo, eles identificam as nuances visuais da cena como parceiros da prática criativa e, com este diferencial, conquistam valorização no mercado de trabalho. Ao lidarmos com pessoas que compreendem como 0 palco funciona e de que modo pode reconstruí-lo cenicamente ganhamos na estética das obras.

No primeiro ano de atividades do Grupo de Pesquisa Alvorada produzimos e apresentamos obras artísticas e textuais em vários estados e também fora do país (Japão). Entretanto, não elaboramos eventos de grande repercussão. Em maio de 2013 realizamos um seminário para alguns convidados, mas não divulgamos amplamente porque queríamos fazer algo maior, com pesquisadores de outras instituições. Porém, no final de 2013 chegamos à conclusão de que poderíamos estimular o estudo de alguns de

nossos de artigos a partir de performances e instalações. A ação-chave do presente escrito surgiu desta necessidade.

\section{Intervenção}

A Intervenção Alvorada ocorreu no Teatro Sesc Jequié (Bahia) nos dias 22 e 23 de Janeiro de 2014 como atividade do Engenho de Composição. Diante de um grupo sagaz de estudantes que em pouco mais de 1 ano produziu e apresentou três artigos em eventos nacionais, discutimos ideias de apresentações artísticas. Vale ressaltar que até então a comunidade da UESB não tinha acessado este acervo plenamente. Aguçá-la através de duas performances e uma instalação pareceu-nos uma boa estratégia e, a existência de um público diverso que envolvia pessoas que não são estudiosas das Artes Cênicas, nos motivou bastante.

Uma imagem é uma visão que foi recriada ou reproduzida. É uma aparência, ou um conjunto de aparências, que foi separada do local e hora em que fez sua primeira aparição e preservada - por alguns momentos ou alguns séculos. Toda imagem incorpora uma forma de ver (Berger, 2008, p.2)

O uso de imagens na Intervenção Alvorada permitiu não apenas acesso a trechos dos artigos como também propôs interações e estímulos variados. A disponibilização de cópias dos textos no foyer do Teatro possibilitou reflexões relacionadas às apresentações. 0 fato de haver um tema norteador -lluminação- propiciou experimentos diversos de modo a demonstrar o vasto campo de estudo. Segue abaixo detalhes dos artigos acompanhados com um número de referência utilizado nas próximas páginas (por último, entre parênteses):

2 Trata-se de um projeto de extensão que, dentre outras ações, pro-picia as apresentações das disciplinas de montagem dos cursos de Licenciatura em Dança e Licenciatura em Teatro da UESB. Coordenação: Prof. Ms. luís Thomaz Sarmento.
3 An image is a sight which has been recreated or reproduced. It is and appearance, or a set of appearances, which has been detached from the place and time in which it first made its appearance and preserved - for a few moments or a few centuries. Every image embodies a way of seeing. (Tradução nossa) 
- Território sem Fronteiras - a luz abre caminhos. Autores: Flávia Santos (licencianda em Dança), Jamile Santana (licencianda em Dança) e Vicente de Paulo (licenciando em Teatro). Resumo: A partir das experiências compartilhadas no IV Encontro "A Luz em Cena - A Formação Técnica e a Academia", realizado pela Universidade do Estado de Santa Catarina- UDESC entre os dias seis, sete e oito de agosto de 2012 nos propomos a refletir sobre iluminação cênica através de práticas no projeto "60 e Assiste - Uma Hora de puro Espetáculo" (UESB). (Artigo 1);

- Um estudo de disciplinas em visualidades nas Licenciaturas de Teatro e Dança das Universidades Públicas Brasileiras. Autores: Everton Paixão e Mabel Almeida. Resumo: Pretende-se nesse estudo colaborar com a prática artística de educadores e estudantes das artes cênicas, identificando a relevância de abordagens visuais no fazer artístico, sem hierarquias: Figurino, Maquiagem, lluminação e Cenário como processos cênicos indissociáveis. (Artigo 2);

- Segurança do Trabalho no Fazer Cênico. Autores: Caio Braga (licenciando em Teatro) e Solange Souza (licencianda em Dança). Resumo: Acreditamos que boa parte do descuido relacionado à montagem cênica pode ser minimizada com a atuação efetiva de quatro personagens: Engenheiro Civil, Gestores, SATED e Técnico de Luz. (Artigo 3).

Os três artigos foram apresentados em Florianópolis no $1^{\circ}$ SE LUZ -Seminário de Estudos de Luz Cênica4, evento realizado pelo Programa de Extensão Luz Laboratório Cênico da Universidade Estadual de Santa Catarina (UDESC).

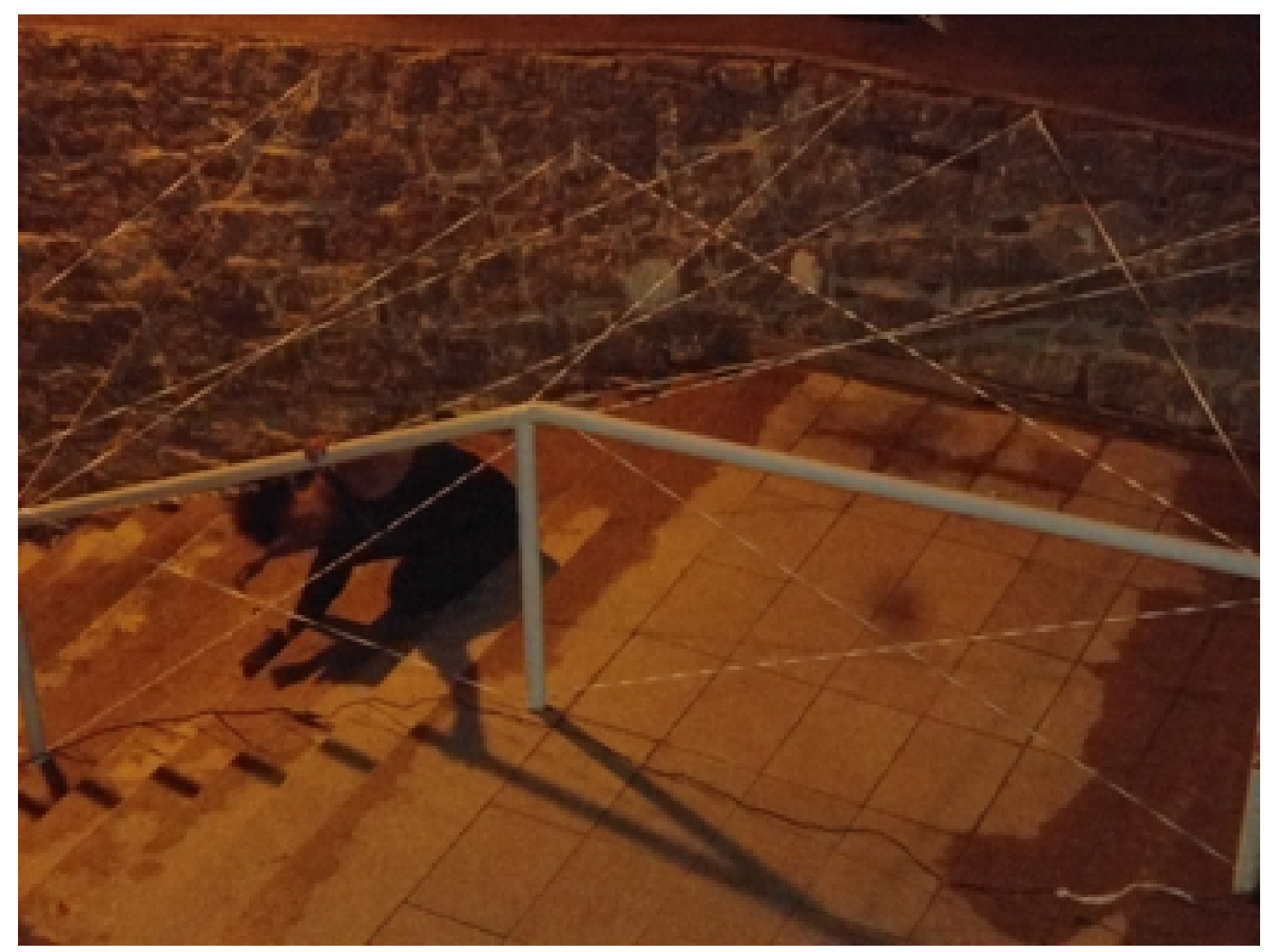

Acervo Alvorada. Artigo 1

4 Paralelo ao $1^{\text {a }}$ SE Luz ocorreu o $5^{\text {a }}$ A luz em Cena também promovido pelo Luz Laboratório. Coordenação geral: Prof. Dr. José Ronaldo Faleiro. Coordenação técnica: Ivo Godois 
A ação de Flávia Santos, Vicente de Paulo e Jamile Santana aconteceu na escada de acesso ao Teatro. O vão da esquerda era utilizado para a movimentação da(o) performer entre o elástico citando trechos do artigo. Em alguns degraus acima uma plataforma com porta giratória reservava dois ambientes: Um com fundo preto e outro amarelo. Um refletor focava essa plataforma de modo que a manipulação do(a) intérprete reforçada pelo texto, mostrava a diferença da incidência da luz nos dois ambientes.

O ingrediente primordial da performance foi a simplicidade. O elástico conotava as dificuldades de trabalhar com lluminação em um espaço sem equipamento e a fala do(a) performer enfatizava esta intenção. A porta giratória serviu como uma metáfora para ilustrar a Sala Zero - espaço da UESB - que passou por reforma, ficando um pouco mais convidativa às experimentações cênicas. A princípio a sala tinha paredes de cor clara e piso de cerâmica. A reforma consistiu na pintura das paredes em preto e instalação de um tablado de madeira.

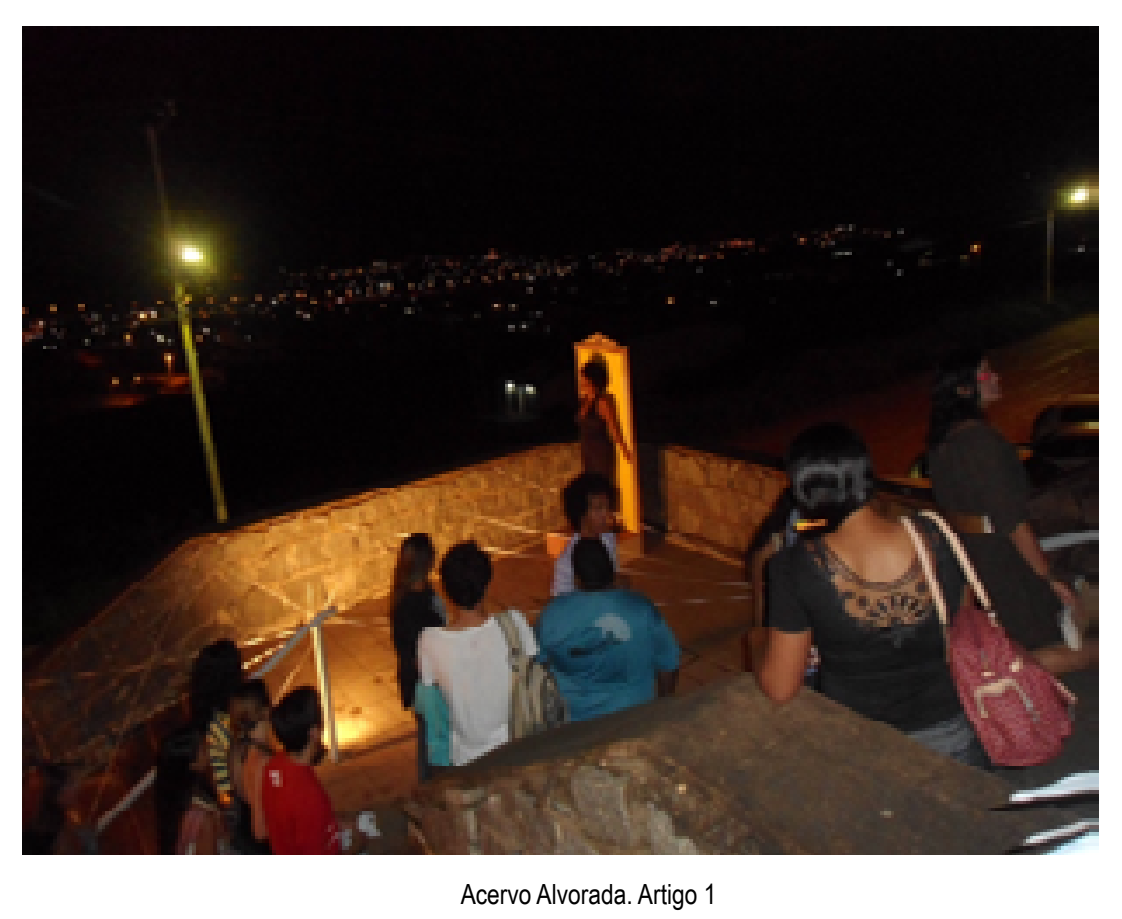

Uma ocorrência que não previmos nessa performance foi a existência de postes que influenciaram no efeito do nosso equipamento de luz. A interação entre diferentes fontes luminosas é comum em apresentações a céu aberto. Logo, bem como nas casas teatrais, precisamos estar atentos sobre o diálogo visual da cena.

[...] A luz artificial - usada no teatro - alimenta e inspira sua utilização na arqui tetura com forte conteúdo expressivo e emocional. A luz que ajuda a construir um espaço, numa linguagem teatral - faz parte da narrativa e reforça o conteúdo emocional pretendido, ou seja, a luz usada como arte assume certa autonomia expressiva [...] (Barbosa, 2011, p.29)

A manipulação do espaço cênico perpassa estudos de lluminação. E, distante de 
negar suas características, identificamos que o ideal é adaptarmos nossas intenções através da inclusão de materiais. No exemplo da performance acima utilizamos dois refletores (um para o corredor de elástico) com intensidade, cor, alcance, angulação e propagação diferente da luz do poste. Estas qualidades tornaram a experiência focada onde queríamos: Na teia de elásticos e na porta giratória.

A ausência de uma narrativa extensa fez com que a performance ocorresse de forma rápida (3 minutos aprox.). O público reagiu de modo a buscar significados, permitindose tempo para a experiência. A aceitação dessa performance surpreendeu porque imaginávamos que o público ia apenas passar para adentrar ao Teatro, sendo que muitas pessoas pararam para entender/vivenciar um pouco mais sobre o que estava acontecendo na escadaria.

Outra característica da Intervenção Alvorada foi a interação com o público. A performance relativa ao artigo 2 contou com luzes que podiam ser manipuladas. Entretanto, poucas pessoas acionaram os dispositivos de luz. $O$ que despertou interesse nessa performance foi o acabamento visual. Conforme Saraiva (1999, p. 20): “Há uma relação íntima entre os figurinos e a cenografia. As cores estão incluídas nessa relação, que poderá ser de contraste ou de harmonia."

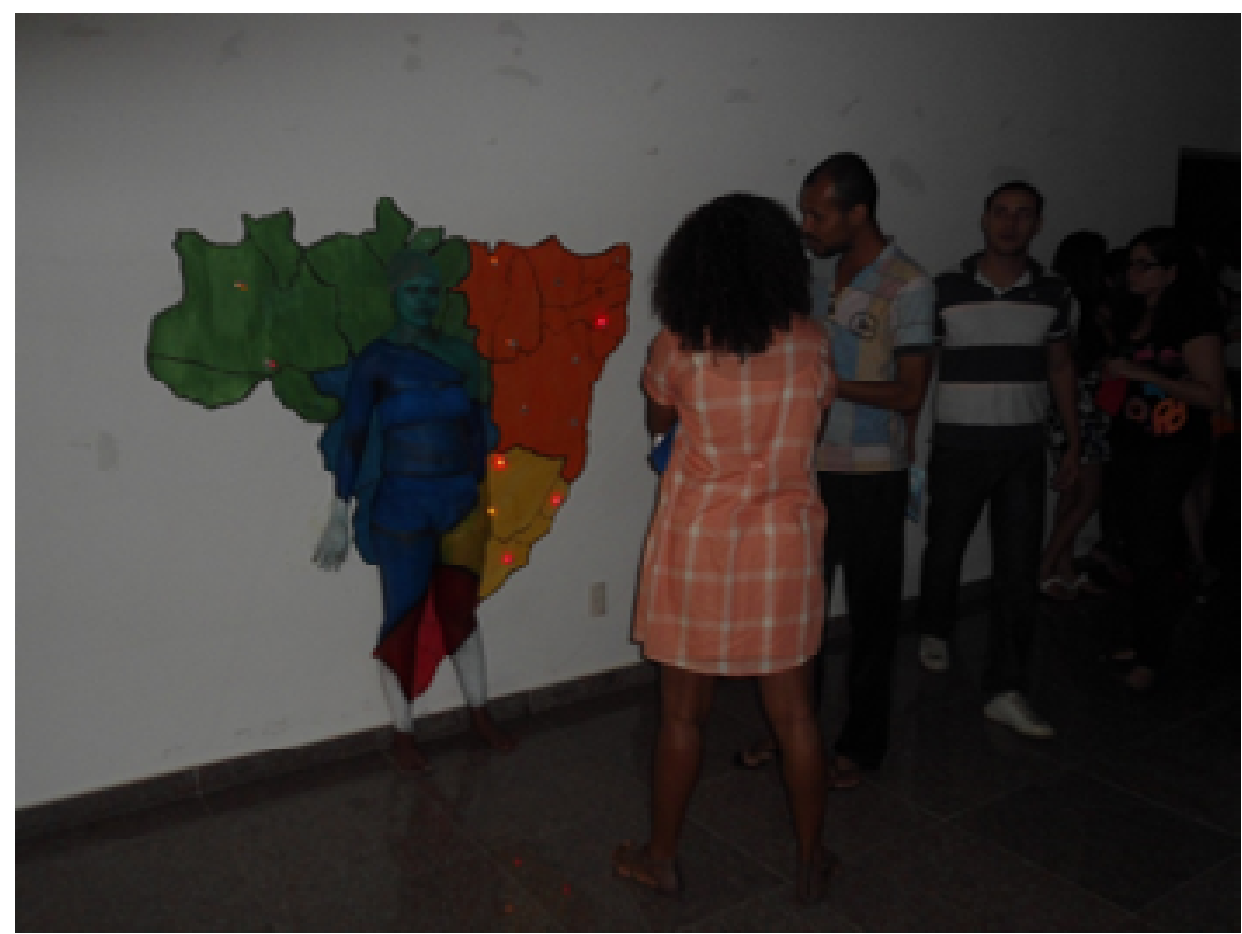

Acervo Alvorada. Artigo 2

A harmonia das cores na camuflagem de Mabel Almeida possibilita questionar as fronteiras entre cenário e figurino. É possível afirmamos que trata-se de um mapa 3D em que a intérprete não é o foco, por mais que o público tenha esse apego devido ao sentimento de empatia e curiosidade.

As luzes no mapa identificam a quantidade de cursos que oferecem disciplinas em visualidades nas cinco regiões do Brasil. Durante a Intervenção, Everton Paixão (de ca 
misa quadriculada em rosa e azul) compartilhava informações acerca do artigo a partir dos comentários do público que quase sempre se concentrava em pequenos grupos, propiciando a abordagem.

\begin{abstract}
Nossa relação de luz e memória está ligada à nossa relação com a luz natural, essencial para nossa sobrevivência em nosso planeta. Nossa memória de luz apre-senta

relação com a natureza, gerando conotações visuais, cromáticas e dinâmicas que funcionam como arquétipos visuais: o espaço branco e frio das geleiras, os raios de luz que penetram entre as árvores de uma floresta, a luz da superfície de um lago na visão submersa, o ouro sem fim da tarde, em matizes dramáticos que desaparecem anunciando o escuro da noite... Todas essas imagens estão as-sociadas

a sentimentos diversos e alimentam aspectos arquitetônicos da luz do dia e da iluminação artificial também. (Barbosa, 2011, p.29-30)
\end{abstract}

A escolha de dispositivos de luz popular, como os encontrados em canetas e brinquedos infantis que funcionam com pilha de relógio, ocorreu pelo baixo custo e também para causar aproximação do público. A associação inerente a cor e intensidade de luz nos foi ensinado desde a infância quando aprendemos a assimilar os sinais do semáforo. Na instalação sob estudo, provocamos um elo de proximidade com o público, mas o impacto da camuflagem foi maior que o efeito de luzes que piscam.

Diante da recepção da instalação podemos afirmar que a sensação de curiosidade arrebatou a audiência. Sem necessidade de entender que tratava-se de uma "mulherdentrodomapa" ou "mapacommulherdentro", o público se permitiu ao deslumbramento da imagem. Tendo nosso principal objetivo ficado em segundo plano, acreditamos que de alguma forma suscitamos reflexões sobre a relação que moveu a pesquisa em pensar cenografia e figurino como possibilidade de criar ambiguidade.

Para além dos estudos das práticas em visualidades, um interesse constante do Grupo de Pesquisa Alvorada foi refletir processos colaborativos a partir dos profissionais que atuam nas obras cênicas. Embora possível, a tarefa de montar um espetáculo de modo compartimentado e autoritário, sem valorizar a liberdade de escolha do outro, parece-nos desnecessário. Um figurinista experiente é capaz de criar sem excesso de informações por parte do coreógrafo/diretor artístico.

Ensaios coletivos, encontros grupais e trocas de experiência são recursos válidos para o entendimento unívoco na construção de um espetáculo. A sombra, assim como luz, colabora na feitura e configuração de uma Dança ou de uma performance teatral.

Percebemos o mundo que nos cerca em três dimensões e sob a luz do sol, que permite ver as formas, cores, e superfícies com desenhos e "manchas de luzes e sombras". A sombra faz parte da luz e nossos cenários cotidianos se mostram em gradações de tonalidades distintas, gerando uma riqueza de estímulos visuais extremamente importante para nossa percepção (Barbosa, 2011, p.28). 


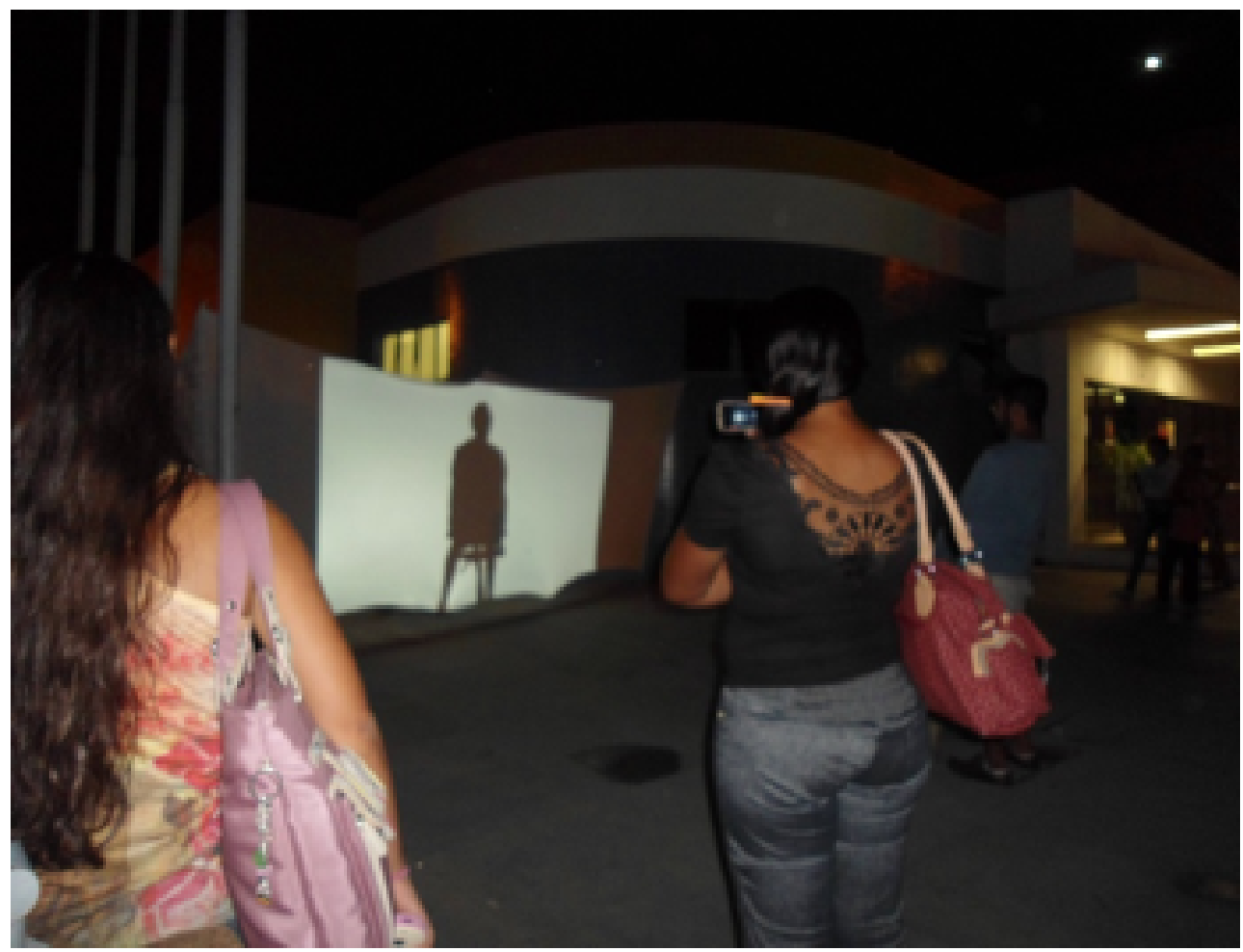

Acervo Alvorada. Artigo 3

O poder de decisão para montagem de uma performance que utiliza apenas sombras como meio de comunicação é de suma importância. Essa condição nos reservou a seleção de materiais simbólicos para discorrer sobre o Artigo 3. A luz de um retroprojetor multimídia por detrás da tela aliado com a partitura corporal e uso de alguns objetos cênicos demarcaram quatro personagens abordados no artigo: Engenheiro, técnico de iluminação, diretor do espaço teatral e gestor do Sindicato dos Artistas e Técnicos em Espetáculos de Diversões do Estado da Bahia (SATED). Apenas na última cena a fala acontece para ratificar uma condição recorrente nas montagens teatrais: O diálogo discorre sobre a preparação de uma ligação de luz que sucumbe num curto circuito.

A proposta de Caio Braga e Solange Almeida ateve estudos espaciais em perspectiva. $O$ movimento de ir e vir dos intérpretes-criadores criou efeitos de profundidade de modo a conotar uma passagem de tempo. O uso de música ritmada, que recorda o cinema mudo, também inspirou a plateia.

[...] A luz elétrica é informação pura. É algo assim como um meio sem mensagem, a menos que seja usada para explicitar algum anúncio verbal ou algum nome. Este fato, característico de todos os veículos, significa que o "conteúdo" de qualquer meio ou veículo é sempre um outro meio ou veículo (Mcluhan, 2001, p.21).

A partir da citação de Mcluhan é possível considerar que a sombra também é uma informação que veicula imagens. Sendo a consequência da luz sob um objeto, a sombra interage com/entre as informações visuais da cena. Neste sentido, a gradação da sombra foi um ponto articulado na performance por possibilitar figuras escuras e também a aparição dos intérpretes-criadores (efeito de transparência), quando muito próximo da tela de projeção. 


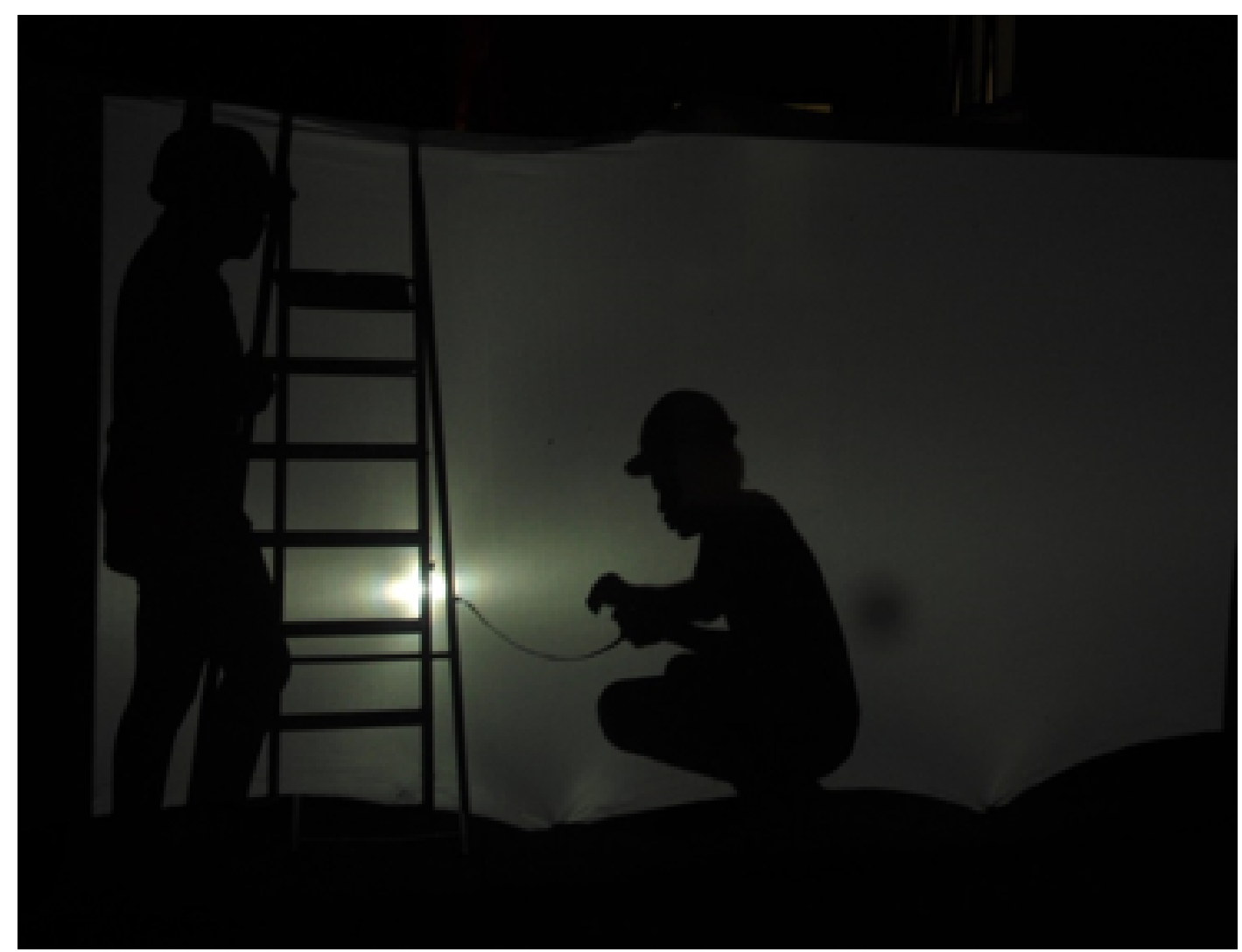

Acervo Alvorada. Artigo 3

Uma vez que a "lluminação" foi o cerne das pesquisas, as produções ultrapassaram as barreiras que destinavam "ilustrar" o texto. De certo modo os artigos foram inspirações recorrentes, mas não atuaram como fins literais das performances e da instalação. Pelo contrário, as apresentações demonstraram formas de interagir com luz em três ações distintas, que aconteceram em sequência, o que possibilitou elos e entrelaçamentos.

A iluminação não deve ser um design que resulte numa leitura interpretativa da cena, inserida momentos antes da estreia. Ao contrário, ela deve nascer com o texto e a cena, deve estar presente desde o primeiro instante em que o ator sobe ao palco, participando ativamente do processo de criação (Camargo, 2010, p. 80)

A Intervenção Alvorada foi exitosa por tornar convidativa a leitura dos artigos e proporcionar interesse para as atividades do grupo. Identificamos ainda a possibilidade de reinvenção do espaço público a partir da luz. Compreendemos que ambientes de passagem são propícios para performances e olhares de reconhecimento e reflexão.

É devido às gradações de luz/sombra que enxergamos a estrutura e o "fio condutor" (diálogo entre as informações cênicas) dos espetáculos de Dança e Teatro. Desta verificação, partimos para um processo de conceituação na tentativa de compreender a obra e eleger as qualidades estéticas. Berger5 (2008, p. 26) propõe que convivemos com uma linguagem de imagens em que, o que importa é quem usa essa linguagem e para qual propósito.

5 The art of the past no longer exists as it once did. Its authority is lost. In its place there is a language of images. What matters now is who uses that language for what purpose. 


\section{Contaminação de estudos}

Os argumentos desse texto e as experiências anteriores e posteriores à ele, me levam a crer que em visualidade, menos é mais. Quanto menos apego em "inovar" com materiais de alta tecnologia ou mesmo "floreios" com várias trocas de instrumentos e/ou efeitos, mais chances de integrar a obra de modo coerente. A grandeza, o excesso, são bem alocados nos estudos preliminares, na liberdade de escolha individual. Mas a partir da troca entre pares (ex.: figurinista $\mathrm{X}$ iluminador), parece-me ideal a seleção mais rigorosa e limitada.

Na perspectiva do fazer cênico, a iluminação desempenha uma condição que ultrapassa a função primária da visibilidade. As variadas intensidades da luz e gama de cores são como uma bússola para a compreensão da obra artística. Neste sentido, o ato de compor a cena imbui a possibilidade de múltiplas atuações na área de visualidade:

Podemos acumular papéis, mas desempenharemos, sempre, pelo menos, um deles.

Um dos mais importantes é, sem dúvida, o do cenógrafo e do figurinista, igualmente essenciais na concepção e na execução (confecção, elaboração) dos objetos cênicos e utilitários, que nos orientam no espaço e se posicionam entre nós e nossa percepção do mundo - e da arte. (Bião, 2009, p.222)

A intermediação de saber proposta por Bião também considera a luz como informação importante da construção cênica. Nas performances tratadas neste escrito é possível afirmar a valorização da luz como fundamental. A criação das performances e da instalação demandou três tarefas: Análise e seleção do local das apresentações, discussões acerca da forma artística e equipamentos necessários e, o mais demorado: A montagem dos mesmos. Excetua-se nesse contexto a performance com projeção de sombras na tela em que experimentamos as imagens com antecedência.

Noto por parte dos estudantes envolvidos na Intervenção Alvorada uma maior consciência e atuação na área de visualidade. Estas qualidades estão atreladas a capacidade de repertório e seleção. A maneira de aprender Teatro ou Dança fazendo é interessante, tal qual assistir e discutir textos que tratam desse fazer. Desse modo, o desejo em busca de mais sabedoria permanece, a curiosidade aflora e novas pesquisas são desenvolvidas.

O que percebo no meu local de trabalho é que por escassez de tempo ou prioridade com o trabalho de dançarino/ator, a experiência de desdobramentos para concepção da obra de modo mais amplo, incluindo a proposta de visualidade (cenário, figurino, maquiagem e iluminação) são restritas. As disciplinas nestes campos ocorrem de modo pontual, em semestres distintos. A existência do Grupo de Pesquisa Alvorada e, consequentes estudos, produções e apresentações decorrentes dele, foram válidos por promover intercâmbios de conhecimento entre pensar/executar/refletir. Creio que esta forma de trabalho cíclico é eficaz para a formação básica e continuada nas Artes Cênicas.

Os profissionais necessários à elaboração artística têm, em sua maioria, domínio em um ou mais signos teatrais e, a partir da especificidade da sua prática, negociam trocas com os demais envolvidos. Nesse trânsito, a iluminação é proposta para relacionar-se com as demais informações cênicas dispostas e também com o 
conjunto da obra, já que é ela que determina a aparência do todo (Sampaio, 2014, p. 71).

Uma atividade recorrente do Alvorada foi gerar discussões sobre a produção dos cursos de Licenciatura em Dança e Licenciatura em Teatro da UESB. Para além disto, mantivemos um fórum-informe com o que vimos e fazíamos no campo das Artes Cênicas articulado com os temas de visualidade. Outro recurso de aprendizagem foi o estímulo às experimentações cênicas. Muitos encontros, principalmente no segundo ano, foram dedicados às práticas artísticas. Estas estratégias ampliaram não apenas

o repertório dos integrantes do grupo e habilidade de compreensão da obra cênica, como também facilitou o entendimento sobre esse e o seu próprio fazer. A partir do escopo apresentado neste escrito permito-me afirmar que estudos em visualidades possibilitam criticidade e engajamento plural, individual e irreversível.

\section{Referências}

BARBOSA, Cláudia Verônica Torres. Percepção da iluminação no espaço da arquitetura: preferências humanas em ambientes de trabalho. São Paulo, 2011. Tese (Doutorado) Faculdade de Arquitetura e Urbanismo, Universidade de São Paulo.

BERGER, John. Ways of Seeing. Peguin Books: Londres, 2008.

BIÃO, Armindo Jorge de Carvalho. Teatro de cordel e formação para a cena: textos reunidos/ Armindo Jorge de Carvalho Bião, Prefácio Jean-Marie Pradier - Salvador: P\&A Gráfica e Editora, 2009.

CAMARGO, Roberto Gil. Processos cênicos coevolutivos. Rebento - Revista de Artes do Espetáculo n². Junho 2010. [suporte eletrônico] Disponível em: http://www.teatrosemcortinas.

ia.unesp.br/\#!/pratas-da-casa/revista-rebento/. Acesso em 06/11/2014.

MCLUHAN, Marshall. Os meios de comunicação como extensões do homem. São Paulo: Cultrix, 2001.

SAMPAIO, Flaviana Xavier Antunes. Dança de Luzes. Vitória da Conquista: Edições UESB, 2014.

SARAIVA, Hamilton F. Interações físicas e psíquicas geradas pelas cores na Iluminação Teatral. Tese. USP: São Paulo, 1999. 